\title{
Globe vésicale évident
}

\section{Obvious full bladder}

\section{P. Ray}

Reçu le 3 janvier 2011 ; accepté le 7 janvier 2011

(C) SFMU et Springer-Verlag France 2011

Figure : Globe vésicale évident chez un patient de 87 ans admis pour détresse respiratoire et marbrures. Le sondage urinaire a ramené $1700 \mathrm{cc}$ d'urines foncées mais stériles. Le choc septique était secondaire à une pneumonie grave.
L'échographie rénale, réalisée devant une insuffisance rénale - probablement fonctionnelle — avec une créatinine à $215 \mu \mathrm{mol} / 1$, n'a pas montré de dilatation des cavités pyélocalicielles.

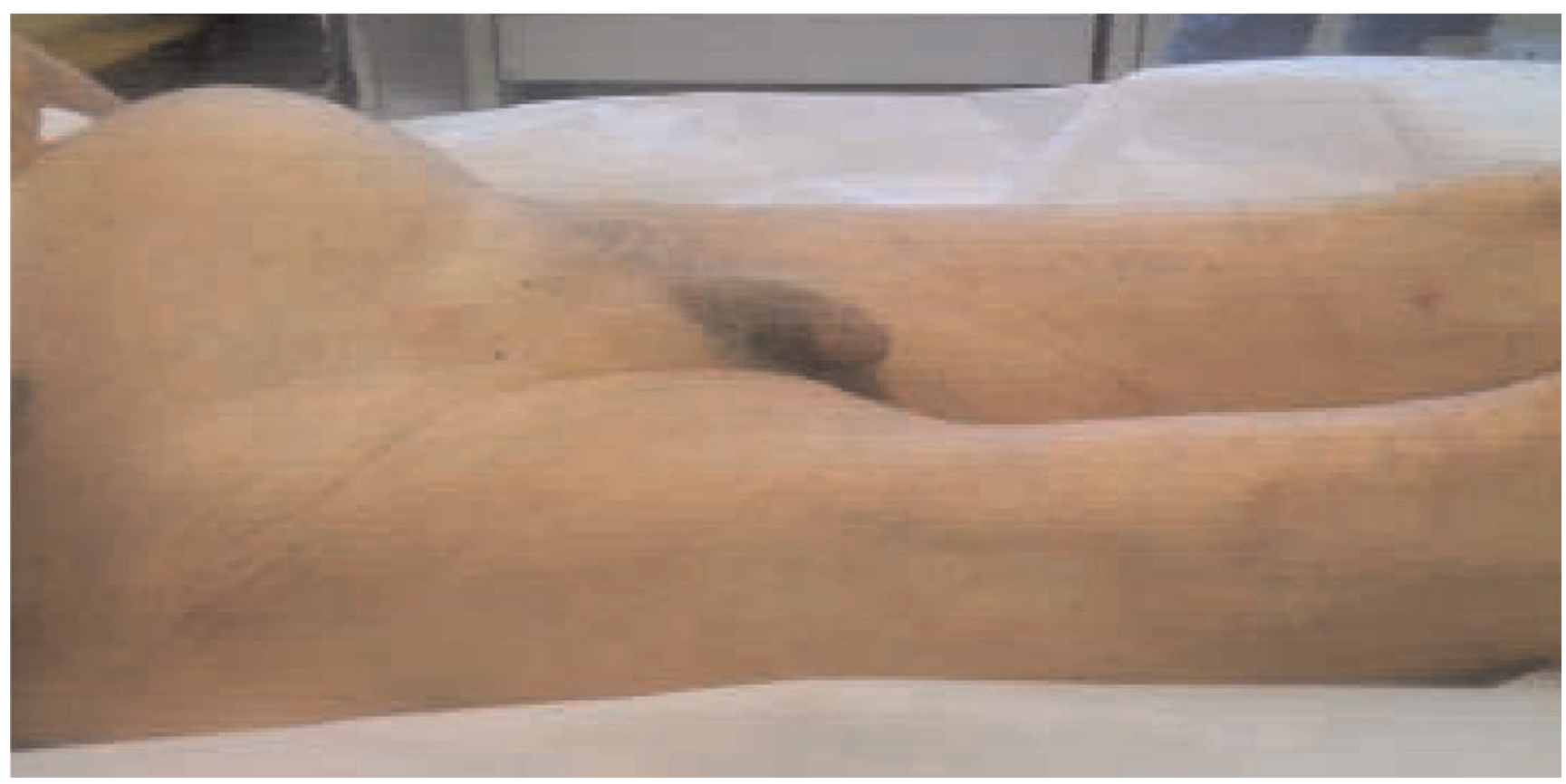

P. Ray $(\square)$

Service d'accueil des urgences,

groupe hospitalier Pitié-Salpêtrière,

AP-HP, UPMC-Paris-VI, 47-83, boulevard de l'Hôpital,

F-75013 Paris, France

e-mail : patrick.ray@psl.aphp.fr 